\title{
Influence of New Media Art on Visual Communication Design
}

\author{
Yuxia Lu \\ Heihe University \\ Heihe, China 164300
}

\author{
Hui Xie \\ Heihe University \\ Heihe, China 164300
}

\begin{abstract}
With the development of era and the changes of people's understanding on life, visual communication design has gained more and more attention. Traditional visual communication design methods have been unable to meet the demand of new era. The development of science and technology has provided new visual communication form, namely the new media art, which is an art form established on the basis of concept. In the eyes of new media artists, only the media creation with creative as the critical foundation can be called artistic creation, and the works realized only through technology are hard to be the public's favorite. New media art is influencing the visual communication art design profoundly. Along with the extensive use of network technology, photographic technology, electronic information technology and digital media technology in design, visual image resources have been developed vigorously. Visual communication art design is no longer just the plane design, which will face many new challenges and opportunities.
\end{abstract}

Keywords—new media art; visual communication design

\section{OVERVIEW OF NEW MEdia ART AND VisuAL COMMUNICATION DESIGN}

Nowadays, new media art has gradually entered into people's life via the network together with the development of digital technology. But in fact, the general public and the people engaged in relevant work of new media have no sufficient understanding toward new media art. So it is necessary for us to understand the basic concepts and characteristics of new media art, to have a more comprehensive understanding of new media art, thus we can better create and use new media art.

New media art is the artistic work created based on digital and network technology, including the common network broadcasting, digital video art, and network animated movie, mobile TV, etc. Some argue that the key for determining whether or not an artistic work belongs to the new media art mainly lies in its mode of transmission, rather than its creativity and ideas. But this view is not accurate, because we can only regard the works with digital network technology but without creativity and core concept as the expression of new media but not the new media art. If we spread an oil painting via $C D$ through the scanning technology, then it cannot be called new media art. Likewise, uploading photos to the network for people's appreciation is not new media art. New media art is that the art works express their creativity and ideas using network and digital media, rather than simply copy.
Each of the development of science will generate great influence on art design field, and at the same time, the art forms with the background of new era will be produced continuously. In the whole development history of art, the development and progress of medicine and human anatomy has provided theoretical basis for the development and mature of drawing, sculpture, and other art forms; the progress of geometry research has enabled the painting perspective theory to develop to new heights, influencing the painting style of many artists at that time and later; the progress of chemical research has provided more painting pigments for oil painters; the further development of optical principle and manufacturing technology has contributed to the birth of photography and art. The development of science and technology has a profound influence on the artistic creation, and science and technology has an important role in promoting art.

Visual communication design refers to the design with visual communication function, which is the art design conveying information through magazines, newspapers and other traditional media and movies, Internet and other new media, so as to conduct the modeling performance. New media art has the characteristics of connection and interaction as it is network-based, which connects people from around the world. New media users often act as different roles, for example, the disseminator of information and the recipient of information, having higher transmission efficiency compared with the traditional media. At the same time, the artists are connected gradually through network with mutual communication, which has promoted the development of visual communication design. The development of new media art has changed the works' creative process and even the final definition. More people have participated in the process of artistic creation more conveniently. And artists no long not create works alone, as more environmental factors and people are involved in.

New media art pioneer Roy Ascot indicated that, the most distinctive features of new media art are connection and interaction. Five processes are needed to really understand the new media art creation: connection, integration, interaction, transformation and appearance. New media allows people to interact with works to the largest extent, so that the transformation between works and people's consciousness can be made better, and eventually produce the brand new relationship, experience and feelings. Therefore, the communication and interaction to the largest extent is the emphasis in new media art creation for artists. 
New media art is a kind of art established based on concept. In the new media artist's view, only the media creation with creativity as the key basis can be called the artistic creation, while the works realized only through technology are hard to become the artistic works appreciated by the public. Expressing the thoughts and ideas through new technology and new media is the core meaning of new media art. New media artists use the new media and art symbols to express their views and to create, and make the idea concrete using new forms. Such new way has produced unprecedented impact on visual communication design, thus more new arts are created thereby. New media artists have changed the previous visual communication design using simple network and electronic application profoundly. Under the influence of new media art, visual communication design is no longer a pure commercial packaging, but has become an effective means of new thoughts and new ideas. New media art has become a bridge between art works and people, and visual communication design has achieved new art height compared with the previous.

The new media era with Internet as the core development has provided wider creation space visual communication designers. The combination of visual communication design and new media has generated profound change on visual communication art, and digital design will be one of the important expression means for visual communication designers in the future. A lot of people haven't really learnt about the great influence generated by the combination of new media art with Internet as the core and visual communication design. Actually if we observe carefully, the influence generated by the combination of visual communication design and Internet is very huge, and our life has undergone profound changes thereby.

In the field of visual communication design, the more important form of interaction design is the network design, of which the advantage is that it can realize two-way communication. People can learn about more detailed contents they are interested in by clicking the mouse while they are browsing information, and have a more comprehensive recognition about the information through further action. The expression of visual communication design interaction needs a creative design. In the whole link, the designer is the integrator of information, connecting people of different backgrounds together by creating a new kind of interpersonal relationship. It seems that what the designer provides is part of a work, rather than a finished product, and the design without interaction has difficulty in expressing the complete and accurate concept. So the interaction of visual communication design in terms of concept requires the integration of people and works, which is the way how people get access to the works, or the ways designer expects people to participate in, which are the important content of design.

The rapid development of computer, network and new media has gone beyond our cognitive capacities. The generation and application of computer has changed many designers' way of creation, and more and more work are conducted relying on computer, which is beyond imagination a dozen years ago. Whether we accept or not, computer has become a necessary tool of the contemporary designers. Also, as a new public information dissemination media, Internet will grow up to be the first mass media in the near future, and visual communication designers will also usher in more challenges. The 21 st century is the age of integration, and also the age with rich tolerance. As for the communications media, the current era is the era of integration of traditional media and new media, and the era focusing on creative media. Visual communication designers need to actively grasp a variety of media, a variety of transmission methods and communication skills, to conduct creation better in the current era. The integration and interesting experience of new media art has injected large amount of fresh elements and vitality into visual communication design, to guide people participate in actively, and to interpret new information content, so as to facilitate complete information conveying, which is the key of the visual communication design under new media era, and strengthen the integration between advertising and people through a variety of means, to better achieve information effect.

\section{AdVANTAgE OF Visual COMMUNiCATION IN NEW MEDIA AGE}

\section{A. Improved Information Transmission Efficiency}

The biggest advantages of Internet are fast transmission speed and wide transmission range. The information can be transmitted to every party of the world through network, and all the necessary information can be obtained via the Internet. Businesses can conduct advertising campaign through the Internet, and such propaganda is global with huge advantages compared with the traditional advertising forms. And visual communication designers can communicate and create via the Internet, which has greatly improved the designer's vision and design level.

\section{B. Abundant Information Content}

The current rapid development of Internet has made everyone really feel the strong function of Internet information, and the information we obtain through internet is very abundant. The new media form gradually mature under new media age has enriched the content of visual communication and user experience greatly.

\section{Diversified Transmission Forms}

The influence and support of network on multimedia technology has rendered diversified visual communication forms. Multimedia technology has integrated the traditional information transmission forms (such as text, voice, images and video) organically, and has improved the shortcomings of traditional media, so as to conduct various information transmissions effectively. As a result, the expression methods and transmission forms have been developed. The visual communication design in future is comprehensive, including the overall design of all human senses, to bring a better result and experience. To a certain extent, the concept of traditional visual communication design has changed.

\section{More Timely}

The Internet has obvious advantage in terms of transmission speed compared with traditional media. So, strong timeliness is one of the advantages of new media. When 
newspapers and magazines are still in print, radio and television are still in post-production, people have received the information release via the Internet. The rapid development of Internet has provided unprecedented information transmission shortcut for visual communication, to make the information transmission timelier.

\section{E. More Interactive}

The Internet is the technology affecting our life the most widely and the easiest one to create interaction. It has changed people's way of interaction from the previous linear to today's network, from one-way communication to the multidirectional communication, and from reality to virtual, and all these are the advantages brought by the Internet's interactive features. The design with strong interaction can arouse people's concern and interest to the greatest extent, and strengthen people's feeling of engagement. People are no longer just the recipients of information, but they have more freedom of choice and participation opportunity. For example, they can respond to the information on the Internet, and feedback to the network media for others to view, at the same time, the interaction opportunities are brought about.

\section{F. More Freedom}

Publishing, printing and distribution are no longer obstacles of visual communication design. So anyone can publish their works in the form of text, voice, image, video and other forms using new media, for the global communication and appreciation. In the era of new media, the outstanding designers don't have to worry about having no opportunities and conditions to show their design. At the same time, the information on the Internet can be modified and improved from time to time, which is other media does not have. We can modify the information on the Internet with more freedom than on other printed books and newspapers.

\section{G. Predictable Communicate Effect}

Traditional information transmission media have ways of evaluation on its coverage, and transmission influence as well as the effect, such as the amount of circulation, audience rating, purchasing volume, etc., while the visual communication design effect under the influence of new media is more scientific, accurate and timely thanks to its various uniqueness. Scientific, effective and timely statistics are beneficial to advertisers and designers to understand the effect and influence of advertising design, playing a very important role in facilitating further improvement of visual communication design.

\section{DEFICIENCIES IN VisUAL COMMUNICATION DESIGN UNDER THE INFLUENCE OF NEW MEDIA ART}

The visual communication design based on new media in the network era is not perfect although it has many advantages. As other design, the visual communication design based on new media is a kind of design with limitation and restrain.

People can select the content they want to browse freely thanks to the interaction characteristics of the network, and the contents online are very rich, people have wider choice alternatives, and new media have no the characteristics of compulsive reading of traditional media. However, it is important to note that this is both strength and shortage. The visual communication design based on network and new media has put forward higher requirements on the designers, so visual communication design is more than just advertising, at the same time, the advertising effecting shall be added, and participate in the optimization of online content, including website content, layout, etc. As specific carries of the Internet, web page is similar to the one page of a book. Due to the limitation of computer display, the layout that can be used is very small, and creative space is limited largely. In this respect, the visual communication design displayed through new media still has great deficiency in terms of visual impact compared with the traditional visual communication design such as the large posters, and outdoor large-scale advertising.

We have already known that the relationship between art and technology is very close in every design field. In the traditional visual communication design based on planar carrier, the relationship between art and technology also very close, but in the context of the Internet age, there are some different elements of visual communication design of new media are needed to be grasped. The expression of such basic elements of visual communication design as text, graphics, images, etc on the Internet has larger limitation that that of the traditional media. It is mainly because that the network information transmission efficiency is largely influenced by the hardware, so the visual communication design elements under the new media era are generally small and exquisite.

\section{CONCLUSION}

Just as the style of art and design is often influenced by the style of painting and sculpture, new media art is generating a far-reaching influence on visual communication art design. Along with the wide application of network technology, photographic technology, electronic information technology and digital media technology in design, visual image resources have developed greatly. Visual communication art design is no longer the plane design, and it will be faced with many new challenges and opportunities. The development of new media art and visual communication design cannot be separated from the development of new technology, and strong correlation exists between them. And although the new media art is different from the visual communication design in essence, it has far-reaching influence on the visual communication design. And its characteristics such as connection, interaction, interesting and high-tech can stimulate visual communication designers' thinking from various aspects, and will bring new changes to the visual communication design field. The current visual communication design is developing rapidly toward the multimedia communication of virtual information image, multi-dimensional performance and the dynamic interactive information transmission field.

\section{REFERENCES}

[1] Lu Ke. Discussion on Influence of New Media Technology on Visual Communication Design in Information Era. Modern Decoration (Theory),2015,No.35304:154-155. 
[2] Wen Zhi. Discussion on Influence of New Media Art on Visual Communication Design Art. Popular Literature,2015,No.36814:93.

[3] Li Li. Discussion on Mobile Art from the Perspective of Visual Communication Design - Study on Mobile Art Visual Communication Form Sense. Packaging World, 2013,No.14601:94-96.

[4] Li Wenbo. Xie Xinhui. Discussion on Challenges Faced by Visual Communication Design Specialty in Digital Era and the Approachestaking UI Interface Design Promotion as an Example. Art and Design (Theory),2013,v.2;No.26408:163-165. 